\title{
Different molecular mechanisms causing 9p21 deletions in acute lymphoblastic leukemia of childhood
}

\author{
Francesca Novara $\cdot$ Silvana Beri $\cdot$ Maria Ester Bernardo $\cdot$ Riccardo Bellazzi $\cdot$ \\ Alberto Malovini $\cdot$ Roberto Ciccone $\cdot$ Angela Maria Cometa $\cdot$ Franco Locatelli $\cdot$ \\ Roberto Giorda $\cdot$ Orsetta Zuffardi
}

Received: 18 March 2009 / Accepted: 19 May 2009 / Published online: 30 May 2009

(C) The Author(s) 2009. This article is published with open access at Springerlink.com

\begin{abstract}
Deletion of chromosome 9p21 is a crucial event for the development of several cancers including acute lymphoblastic leukemia (ALL). Double strand breaks (DSBs) triggering 9p21 deletions in ALL have been reported to occur at a few defined sites by illegitimate action of the $\mathrm{V}(\mathrm{D}) \mathrm{J}$ recombination activating protein complex. We have cloned 23 breakpoint junctions for a total of 46 breakpoints in 17 childhood ALL (9 B- and 8 T-lineages) showing different size deletions at one or both homologous chromosomes 9 to investigate which particular
\end{abstract}

Electronic supplementary material The online version of this article (doi:10.1007/s00439-009-0689-7) contains supplementary material, which is available to authorized users.

F. Novara $\cdot$ R. Ciccone $\cdot$ O. Zuffardi $(\bowtie)$

Biologia Generale e Genetica Medica,

Università degli Studi di Pavia,

Via Forlanini, 14, 27100 Pavia, Italy

e-mail: zuffardi@unipv.it

\section{S. Beri · R. Giorda}

Istituto Scientifico "Eugenio Medea",

Bosisio Parini, Lecco, Italy

M. E. Bernardo $\cdot$ A. M. Cometa $\cdot$ F. Locatelli

Oncoematologia Pediatrica,

Fondazione IRCCS Policlinico San Matteo,

Università degli Studi di Pavia, Pavia, Italy

R. Bellazzi · A. Malovini

Dipartmento di Informatica e Sistemistica,

Università degli Studi di Pavia, Pavia, Italy

O. Zuffardi

Fondazione IRCCS Policlinico San Matteo, Pavia, Italy sequences make the region susceptible to interstitial deletion. We found that half of $9 \mathrm{p} 21$ deletion breakpoints were mediated by ectopic $\mathrm{V}(\mathrm{D}) \mathrm{J}$ recombination mechanisms whereas the remaining half were associated to repeated sequences, including some with potential for non-B DNA structure formation. Other mechanisms, such as microhomology-mediated repair, that are common in other cancers, play only a very minor role in ALL. Nucleotide insertions at breakpoint junctions and microinversions flanking the breakpoints have been detected at 20/23 and $2 / 23$ breakpoint junctions, respectively, both in the presence of recombination signal sequence (RSS)-like sequences and of other unspecific sequences. The majority of breakpoints were unique except for two cases, both T-ALL, showing identical deletions. Four of the 46 breakpoints coincide with those reported in other cases, thus confirming the presence of recurrent deletion hotspots. Among the six cases with heterozygous $9 p$ deletions, we found that the remaining $C D K N 2 A$ and $C D K N 2 B$ alleles were hypermethylated at $\mathrm{CpG}$ islands.

\section{Introduction}

Unraveling the cause of genomic structural rearrangements has become a hot topic in human genetics. The comprehension of the nucleotide sequences leading to genomic instability might ultimately lead to understand whether deleterious imbalances, both constitutional and acquired, occur at random in people sharing apparently identical genome sequences at a certain locus or are linked to specific haplotypes. In the last years three major mechanisms had been proposed, i.e., non-allelic homologous recombination (NAHR), responsible for recurrent rearrangements, non-homologous end joining (NHEJ), and Fork Stalling 
and Template Switching (FoSTeS), the latter two associated with non-recurrent rearrangements ( $\mathrm{Gu}$ et al. 2008). Most of these mechanisms had been extrapolated by studying patients with constitutional imbalances. Very few studies have focused on the molecular mechanisms leading to acquired rearrangements although their importance in tumor's initiation and progression is obvious as recently demonstrated by the finding that the acquired JAK2V617F mutation, in myeloproliferative neoplasms, is associated with a germline haplotype block that includes the $3^{\prime}$ portion of JAK2 (Jones et al. 2009; Olcaydu et al. 2009; Kilpivaara et al. 2009). This finding indeed implies the existence of a strong, but uncharacterized, interaction between somatic and germline genetics (Campbell 2009). We cloned 23 breakpoint junctions, for a total of 46 breakpoints, in 17 ALL of childhood (9 B- and 8 T-lineages; $2-4$ breakpoints per case according to the presence of different heterozygous/homozygous deletions) showing non-recurrent deletions at one or both homologous chromosomes 9; all deletions contained $C D K N 2 A$, most also involved $C D K N 2 B$. These 9p21.3 genes encode three cell cycle inhibitory proteins: $\mathrm{p} 15^{\mathrm{INK} 4 \mathrm{~b}}, \mathrm{p} 16^{\mathrm{INK} 4 \mathrm{a}}$, and $\mathrm{p} 14^{\mathrm{ARF}}$ (Gil and Peters 2006). Homozygous deletions removing p16 or heterozygous deletions with inactivation of the normal allele occur in a variety of cancers (Drexler 1998; Ruas and Peters 1998; Orlow et al. 1999; Bertin et al. 2003; Irving et al. 2005; Murao et al. 2006; Kohno and Yokota 2006; Strefford et al. 2007; Usvasalo et al. 2008; Bungaro et al. 2009). Therefore, this locus is considered a paradigm of the two-hit hypothesis (Knudson 1971). In the last years, both lymphoid leukemias and other types of tumors have been analyzed for the 9p21 deletion (Kitagawa et al. 2002; Florl and Schulz 2003; Sasaki et al. 2003; Kohno and Yokota 2006). Kohno and Yokota (2006) mapped the breakpoints of 21 lymphoid leukemia cases, 21 lung cancer cases, and 32 other solid cancer cases at a $10-\mathrm{kb}$ resolution. They found that regions of breakpoint clustering were different in different malignancies and that the majority of the 20 cloned breakpoints in lymphoid leukemia clustered at a few breakpoint sites, each <15-bp in size. The sites were flanked by sequences similar to the heptamer-RSSs which are targeted by the RAG complex in V(D)J recombination, as previously shown also by Cayuela et al. (1997).

While screening by genome-wide array-CGH a bone marrow sample of 65 childhood B- and T-ALLs, we detected 18 cases $(27.7 \%)$ having either heterozygous or homozygous 9 p21 deletions. We then performed a detailed analysis of breakpoint junctions in only 17 of them (9 Band 8 T-ALLs) in order to better understand which particular sequences make the $9 \mathrm{p} 21$ region susceptible to interstitial deletions. Moreover, we have studied, by $\mathrm{CpG}$ island methylation analysis, the activation/inactivation state of $C D K N 2 A$ and $C D K N 2 B$ in heterozygous deletions.

\section{Materials and methods}

Patients

Sixty-five pediatric patients, aged between 4 months and 18 years (median age 5 years and 3 months), were included in the first screening through whole-genome array-CGH at a 100-kb resolution (Kit 44B, Agilent Technologies, Santa Clara, CA). Of the 65 children, 53 were affected by B-ALL, whereas 12 had T-lineage ALL (see Supplementary Table 1 for patients characteristics). All patients were diagnosed and treated in a single center (Oncoematologia Pediatrica Fondazione IRCCS Pavia, Italy) according to the front-line protocol of the Italian Association of Pediatric Hematology and Oncology (AIEOP) for childhood ALL (AIEOP LLA 2000) or the relapse protocol (AIEOP LLA REC 2003), with the only exception of a 4-month-old child who received chemotherapy according to the Interfant 99 protocol (Pieters et al. 2007). The study received approval by the local Institutional Review Board, and informed consent was obtained from all patients' parents. Patients were censored as of 1 August 2007, the median follow-up time being 3.3 years (range 3-78 months).

The diagnosis of ALL was based on morphological, cytochemical, and immunophenotypical criteria. Eligible patients had fewer than 3\% blasts positive for myeloperoxidase or Sudan black, and were negative for non-specific esterase according to the French-American-British criteria. Positivity criteria for immunophenotyping were defined according to the BFM-family criteria, with the limits of $20 \%$ for surface antigens and 10\% for intracellular markers (van der Does-van den Berg et al. 1992). The presence of the translocations $t(9 ; 22)$ and $t(4 ; 11)$ was systematically screened by reverse transcriptase-polymerase chain reaction (RT-PCR) in a centralized laboratory (van Dongen et al. 1999). CR was defined as the absence of physical signs of leukemia or detectable leukemia cells on blood smears, a BM with active haematopoiesis and fewer than 5\% leukemia blast cells and normal cerebrospinal fluid.

Patients with 9p21 deletions were selected from the first screening: ten were affected by B-ALL and 8 with T-ALL.

\section{Customized array-CGH}

Each childhood ALL sample was analyzed with a 44B Agilent platform for genomic array having in average an oligomer every $35-\mathrm{kb}$. Because the minimum positive call was considered three consecutive oligomers with a $\log _{2}$ ratio different from zero [cut-off $\log _{2}$ ratios: -1 and -4 for constitutional heterozygous and homozygous deletions, respectively; +0.5 for constitutional duplications; +1 for constitutional triplication; $\log _{2}$ ratio of -0.3 is representative of a cellular mosaic of about $50 \%$, as 
demonstrated by dilution experiments (data not shown)], the true resolution of the platform was about $100-\mathrm{kb}$. As reference DNA we used a pool of female or male lymphocytes (Promega, Milan, Italy). All CNVs not reported in the database of genomic variants (http://projects.tcag.ca/ variation/) and not already known to be associated with leukemia were confirmed as de novo or acquired with a new array experiment using patient's saliva as reference DNA. Each case with 9p21 deletion was reanalyzed on a customized platform generated using the eArray software (http://earray.chem.agilent.com/); the probes (60-mer oligonucleotides) were selected from those available in the Agilent database and are specific for the $9 \mathrm{p} 21$ region. The array was made of 44.000 probes (custom 44K, Agilent Technologies) of which 19.000 represented the region under study (from 19 to $25 \mathrm{Mb}$ ), allowing molecular profiling of 9 p21 aberrations with a resolution of $\sim 1$ and $\sim 10-\mathrm{kb}$ in single copy and repeated regions, respectively. DNA of every ALL sample was extracted from bone marrow (BM) mononuclear cells with at least $80 \%$ of blasts (range $80-100 \%$, median value $90 \%$, evaluated morphologically and through flow cytometry), after gradient separation, or peripheral blood ( $\mathrm{PB}$, only when the presence of leukemia blasts in the periphery was equal to or superior than 80\%) using a QIAamp DNA Blood Mini Kit (Qiagen, Milan, Italy) according to the manufacturer's protocol. Test DNA (from leukemia BM or PB leukemia cells, $500 \mathrm{ng}$ ) and control DNA (Human Genomic DNA Female or Male, Promega, Madison, WI, 500 ng) were double-digested with $R s a \mathrm{I}$ and AluI (Promega) for $1 \mathrm{~h}$ at $37^{\circ} \mathrm{C}$. After digestion, samples were incubated at $65^{\circ} \mathrm{C}$ for $20 \mathrm{~min}$ to inactivate the enzymes then labeled by random priming (Agilent Technologies) for $2 \mathrm{~h}$ using cyanine5dUTP for the test DNA and cyanine3-dUTP (Agilent Technologies) for the control DNA. Labeled DNAs were incubated at $65^{\circ} \mathrm{C}$ for $10 \mathrm{~min}$ and then cleaned with Microcon YM-30 filter units (Millipore, Billerica, MA). Purified samples were brought to a total volume of $21 \mu \mathrm{l}$ in $1 \times \mathrm{TE}$ ( $\mathrm{pH} 8.0$, Promega), and yield and specific activity were determined for each sample using a NanoDrop ND-1000 UV-VIS Spectrophotometer (Agilent Technologies). The appropriate cyanine 5- and cyanine 3-labeled samples were combined in a total volume of $39 \mu \mathrm{l}$. After sample denaturation and pre-annealing with $5 \mu \mathrm{l}$ of Human Cot-1 DNA (Invitrogen, Carlsbad, CA), hybridization was performed at $65^{\circ} \mathrm{C}$ with shaking for $24 \mathrm{~h}$. After two washing steps, the array was analyzed on the Agilent scanner (DNA Microarray Scanner with Sure Scan HighResolution Technology, Model G2565CA, Agilent Technologies) and then by the Feature Extraction software (v9.1). Graphical overview was obtained using the CGH analytics software (v3.4.27). The positions of oligomers refer to the Human Genome March 2006 assembly (hg18).
Results were also visualized using the UCSC Genome Browser website (http://genome.ucsc.edu/).

\section{Breakpoint mapping}

Breakpoints were cloned by long range PCR using primers that recognize sequences flanking the distal and proximal breakpoints, respectively, based on the customized arrayCGH data. All primer sequences are available on request.

Long-range PCRs were performed with JumpStart Red ACCUTaq LA DNA polymerase (Sigma-Aldrich, Steinheim, Germany) and the following protocol: $30 \mathrm{~s}$ at $96^{\circ} \mathrm{C}$, 35 cycles of $15 \mathrm{~s}$ at $94^{\circ} \mathrm{C} / 20 \mathrm{~s}$ at $58^{\circ} \mathrm{C} / 10 \mathrm{~min}$ at $68^{\circ} \mathrm{C}$, $5 \mathrm{~min}$ final elongation time. Sequencing reactions were performed with a BigDye Terminator Cycle Sequencing kit (Applied Biosystems, Foster City, CA) and run on an ABI Prism 3130xl Genetic Analyzer.

\section{DNA methylation assay}

Sodium bisulfite conversion of unmethylated cytosine residues to uracil in DNA samples (700 ng) was performed using a DNA Methylamp ${ }^{\text {TM}}$-One step-DNA modification kit (Epigentek, Brooklyn, NY) according to the manufacturer's protocol. Primers for $C D K N 2 A$ and $C D K N 2 B$ were designed with $\mathrm{CpG}$ Ware software (http://apps.serologicals.com/cpgware/dna_form2.html) to specifically amplify each of the sequences, based upon chemically induced differences. Methylation-specific polymerase chain reaction (MS-PCR) amplification was carried out using primers specific for either wild-type, methylated or unmethylated DNA (see Supplementary Table 4 for details). The PCR mixture contained $10 \times$ Taq reaction buffer $(200 \mathrm{mM}$ Tris $\mathrm{pH} 8.4$, $500 \mathrm{mM} \mathrm{KCl}$ ), $50 \mathrm{mM} \mathrm{MgCl}_{2}$ (final concentration $1.5 \mathrm{mM}$ ), $10 \mathrm{mM}$ dNTPs mixture (final concentration $0.2 \mathrm{mM}$ each), $20 \mathrm{mM}$ primers (300 ng each per reaction), 1.5 units of Taq DNA polymerase (all material from Invitrogen, Carlsbad, CA) and bisulfite-modified ( $\sim 100 \mathrm{ng})$ or unmodified DNA $(\sim 100 \mathrm{ng})$ for a final volume of $30 \mu \mathrm{l}$. PCR specific for unmodified DNA also included $0.5 \mathrm{M}$ betain (Sigma-Aldrich, Steinheim, Germany). Amplification was carried out in a thermocycler, with the following PCR cycling profile: preheating at $96^{\circ} \mathrm{C}$ for $5 \mathrm{~min}$, followed by $95^{\circ} \mathrm{C}$ for $30 \mathrm{~s}$, annealing temperature for $30 \mathrm{~s}$ (see Supplemenray Table 4 for each annealing temperature), $72^{\circ} \mathrm{C}$ for $30 \mathrm{~s}$ for 35 cycles, and a final extension at $72^{\circ} \mathrm{C}$ for $7 \mathrm{~min}$. The PCR samples were loaded onto a $2.5 \%$ agarose gel, stained with ethidium bromide, and directly visualized under ultraviolet (UV) illumination. MS-PCR was also performed on five positive controls whit 9p21 deletions, detected by whole-genome array-CGH, from other different type of cancers and on the same number of negative controls. 
To confirm the methylation state of $C D K N 2 A$ and $C D K N 2 B$, an aliquot of each PCR product was cut with BstUI (New England Biolabs, Beverly, MA), which recognizes the sites of methylation (5'...CGCG...3' and $3^{\prime} \ldots$ GCGC ... $5^{\prime}$ ), for $1 \mathrm{~h}$ at $60^{\circ} \mathrm{C}$, then loaded on a $2.5 \%$ agarose $1 \times \mathrm{TAE}$ gel. Cleavage occurs if the CGCG sequence has been retained during bisulfite conversion due to the methylated status of the cytosine residues. A second aliquot of the PCR products was purified with UltraClean PCR Clean-up (MoBio. Labs, Carlsbad, CA) according to the manufacturer's protocol and sequencing reactions were performed by automated DNA Sequencing (PE Applied Biosystem).

\section{Results}

Genome-wide array-CGH analysis detected several copy number aberrations in $90.7 \%$ (59/65) of the cases (Supplementary Table 2). The most frequent imbalances involved 6q16.2-q21 (5 cases), 12p13.1-p13.2 (13 cases, of which 9 encompassing $C D K N 1 B$ ), and $14 \mathrm{q} 32.33$ encompassing the IgH locus (30 cases). All these imbalances are beyond the aims of this study but they are summarized in Supplementary Table 2 . The frequency of homozygous/heterozygous 9p21 deletions was $27.7 \%$ (18/65) and was higher in T-ALLs than in B cell precursor ALLs [66.7\% (8/12) vs. $18.9 \%(10 / 53)]$. In most samples, the $\log _{2}$ ratio was between -0.3 and -0.8 for heterozygous and between -2 and -3.5 for homozygous deletions, due to normal cells contamination. Customized array-CGH experiments confirmed the data obtained on the $44 \mathrm{~K}$ platform and allowed us to better characterize the size of each deletion (Fig. 1; Supplementary Table 3). The region between the last normal and the first deleted oligomeres ranged between $51 \mathrm{bp}$ and $7.8 \mathrm{~Kb}$. Deletion size and location were different in all cases, except for two cases characterized by a deletion with proximal and distal identical breakpoints (888-06 and 314-07, Supplementary Table 3). Cloning of the breakpoint junctions allowed us to characterize the precise size of each deletion (Fig. 2a) and to identify the sequences flanking each breakpoint junction (Table 1). All deletions always spanned at least $C D K N 2 A$ and either $C D K N 2 B$ or MTAP (Fig. 2b). In one case (1329-07), the shorter $C D K N 2 A$ isoforms were not deleted. When heterozygous deletions of $C D K N 2 A$, or both $C D K N 2 A$ and $C D K N 2 B$, were present (6 cases: 888-06, 46-07, 1623-06, 1329-07, 886-07 and 547-07; Fig. 2a; Supplementary Table 3), the remaining allele was always methylated at its promoter $\mathrm{CpG}$ island (Fig. 3). Twenty-three 9p21 breakpoint junctions (for a total of 46 breakpoints) were cloned from only 17 childhood acute lymphoblastic leukemia cases, 8 T- and 9 B-ALLs (Table 1), because the cloning failed for one B-ALL (case 884-07). Junctions were cloned from 11 cases with two breakpoints (either heterozygous deletions or identical homozygous deletions), 4 cases with four breakpoints (heterozygous/homozygous deletions with different breakpoints) and 2 cases (888-06 and 31407) with multiple deletions on the same allele for a total of four breakpoints per case. One B-ALL case (402-06), analyzed both at onset and relapse, presented identical 9p21 deletion breakpoints. Only one T-ALL case (1460-07, BP1) showed a breakpoint junction with an overlap of six nucleotides, evidence of microhomology-related rearrangement. Two junctions, one from a T-ALL case (156206) and one from a B-ALL case (1327-07) had neither insertions nor nucleotide overlaps. A de novo insertion 1-12 nucleotides in size (average 4.8 nucleotides, $\mathrm{T}$ cells 4.4 nucleotides, $\mathrm{B}$ cells 5.3 nucleotides) was present at all other breakpoint junctions. One T cell leukemia (219-07, BP1) had at its proximal breakpoint a $227 \mathrm{bp}$ inversion preceded by three extra nucleotides not present in the consensus sequence. The second allele from the same subject (219-07, BP2) contained a 427 bp insertion from chromosome 4q32.2. A B-ALL case (1623-06) carried at its distal breakpoint a 253 bp inversion bracketed by 15 bp of duplicated inverted sequence and followed by seven extra nucleotides not present in the genomic consensus sequence. Two T-ALL cases (547-07 and 217-07) had essentially the same junctions, with distal breakpoints one base apart in an Alu repeat and proximal breakpoints in the same $(\mathrm{TG})_{n}$ repeat; both cases had de novo insertions: AGG in one, TTTAAGTAAG in the other. A third B-ALL case (46-07) had its proximal breakpoint in the same $(\mathrm{TG})_{n}$ repeat. Two cases (888-06 and 314-07) carried two deletions on the same chromosome, one spanning $C D K N 2 A$, the other more proximal (BP2: 22486528 to 22494344). Sequence analysis of the second deletion showed that both cases had the same breakpoints. Deletion-specific PCR amplification of 21 healthy controls (not shown) demonstrated that the deletion was present in 12 of them and should, therefore, be considered a genomic polymorphism. Copy number variations in the same interval are listed in the Database of Genomic Variants (http:// projects.tcag.ca/variation/) (Iafrate et al. 2004) as Variation_37473 (Cooper et al. 2008) and Variation_7739 (de Smith et al. 2007).

All repeated sequences located within $60 \mathrm{bp}$ from the breakpoints are listed in Table 1 . Twenty-seven of the 46 breakpoints $(58.7 \%)$ are actually inside a repeat. The more frequent family of repeats was LINE (12 breakpoints; T: 3; B: 9); SINE (5 breakpoints; T: 3; B: 2), simple repeats (4 breakpoints; T: $3 ; \mathrm{B}: 1)$, DNA (3 breakpoints; T: 2; B: 1) and LTR (3 breakpoints; T: 2; B: 1) were also represented. In 11 junctions, repeats were present at both breakpoints; in nine junctions, at 

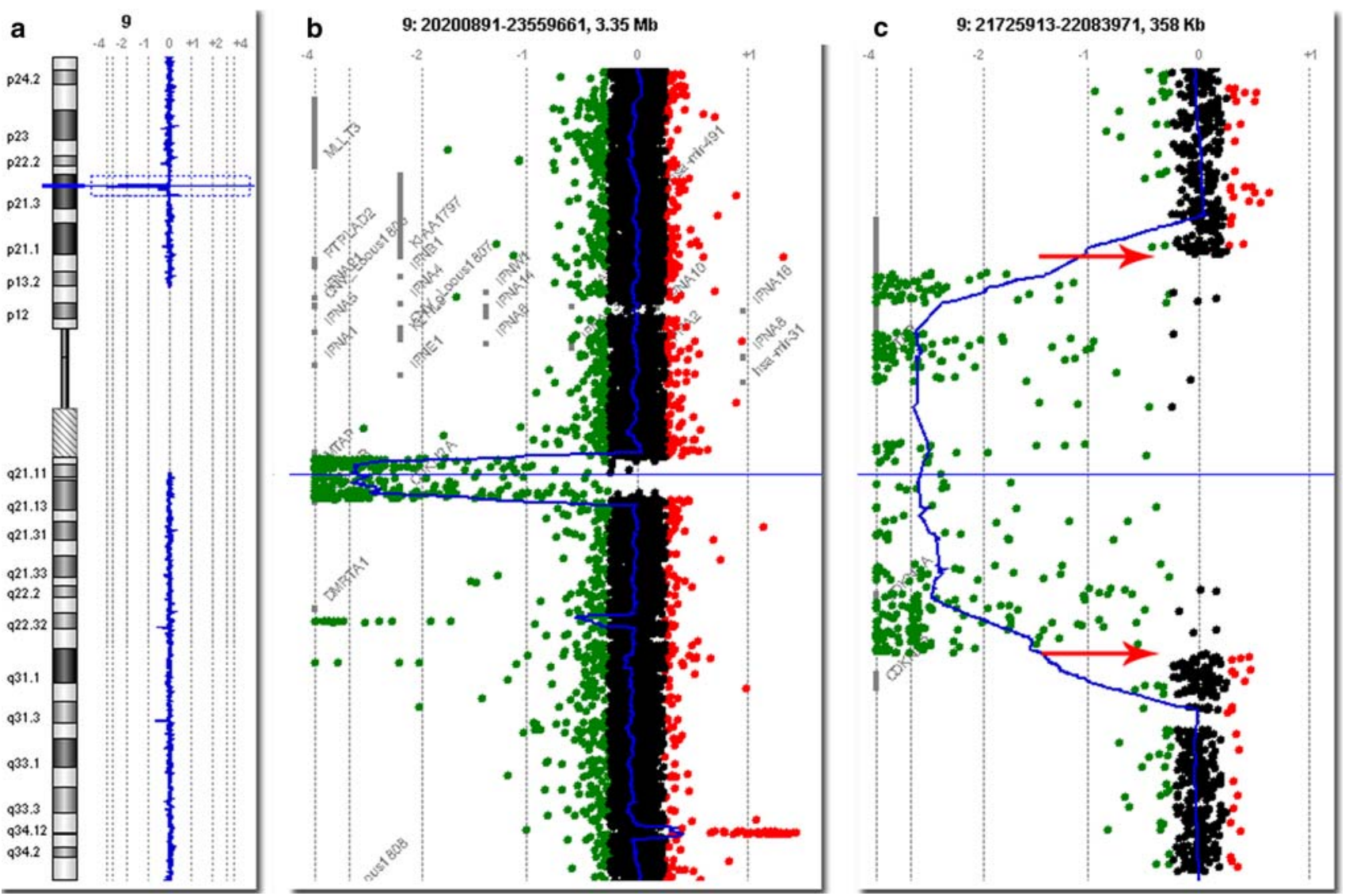

Fig. 1 An example of custom array-CGH results: case 217-07. a Chromosome 9 profile with $9 \mathrm{p} 21$ deletion indicated by the box, $\mathbf{b}$ enlargement of the 9p21 region showing a homozygous deletion, $\mathbf{c}$ further enlargement

one breakpoint; in three junctions, no repeats were involved.

To assess the involvement of illegitimate $\mathrm{V}(\mathrm{D}) \mathrm{J}$ recombination in 9p21 deletions, RSS-like sequences were examined. The $23 \mathrm{bp}$ sequence flanking each breakpoint was visually searched for $5^{\prime}$-CAC trinucleotides in the forward direction and the $3^{\prime}-$ GTG trinucleotides in the reverse direction. This choice was due to the fact that the CAC trinucleotide in the heptamer-RSS (CACAGTG) is the only part of the RSSs indispensable for V(D)J recombination (Hesse et al. 1989; Akamatsu et al. 1994) and nucleotide loss as a result of $\mathrm{V}(\mathrm{D}) \mathrm{J}$ recombination does not extend over $20 \mathrm{bp}$ (Nobori et al. 1996). Sequences similar to the nonamer RSS (ACAAAAACC) were also considered. RSSs sequences were found at 12/24 breakpoints in our T-ALL cases and in 12/22 breakpoints in B-ALLs (Table 1).

\section{Discussion}

In the past few years, several studies have focused on understanding the origin of deletions and duplications leading to both benign and pathogenic copy number variations of the locus under study; the arrows point to the edge between normal and deleted oligomeres

(CNVs). Some constitutional CNVs are obviously of meiotic origin (Turner et al. 2008; Gu et al. 2008). For what concerns acquired CNVs, it seems now very clear that they are not limited to tumor processes. The concept of a stable somatic genome has been challenged by the finding of extensive genomic copy number variation in mouse embryonic stem cells suggesting a similar situation in humans (Liang et al. 2008). These data reinforced previous studies showing that mitotic ectopic exchanges occurring in the soma and germ line mainly contribute to de novo occurrence of human alpha-globin genes duplications, whereas meiotic exchanges between homologous chromosomes generate a minority of sperm duplications (Lam and Jeffreys 2007). Somatic CNVs occurrence has also been demonstrated by the finding that identical twins can differ in CNV (Bruder et al. 2008). Deletions at 9p21 deserve attention because removal of the p16 tumor suppressor gene is a genetic alteration frequently observed in a variety of human cancers (Drexler 1998; Ruas and Peters 1998; Orlow et al. 1999; Bertin et al. 2003; Irving et al. 2005; Murao et al. 2006; Kohno and Yokota 2006; Strefford et al. 2007; Usvasalo et al. 2008; Bungaro et al. 2009). Kohno and Yokota (2006) reported that DNA double strand breaks (DSBs) triggering 
Fig. 2 a Graphic representation of the 9p21.3 deletions in all 18 cases. Grey lines represent the deleted region of every allele of each case. Overlap of two lines for the same case indicates a

homozygous deletion. b Detailed map of the MTAP/CDKN2A/

$C D K N 2 B$ region. The ten cases whit homozygous/heterozygous deletions, whose breakpoints (at least one) map between $21,800,000$ and 22,100,000 bp, are reported

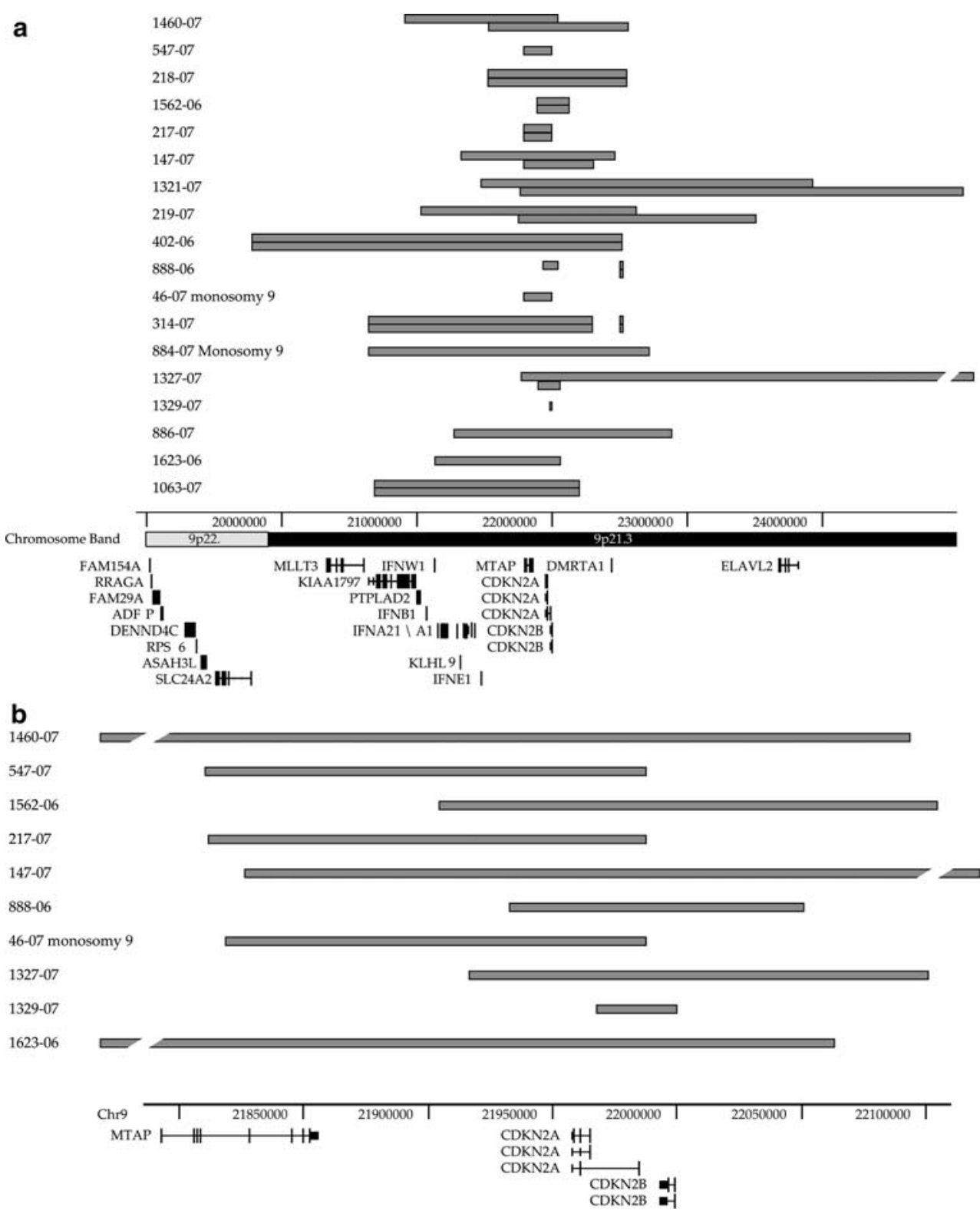

9p21 deletions in lymphoblastic leukemia lines are formed at a few defined sites by the illegitimate action of the recombination-activating genes (RAG) protein complex in $\mathrm{V}(\mathrm{D}) \mathrm{J}$ recombination, as previously reported (Cayuela et al. 1997), while 9p21 DSBs in solid tumor lines are formed at unspecific sites by microhomology-mediated mechanisms.

In our whole-genome array-CGH screening of 65 childhood ALL, we found 9p21 deletions in 18 cases, corresponding to a frequency of $27.7 \%$, comparable to the $29 \%$ reported by Bungaro et al. (2009) in a pediatric ALL sample analyzed with a similar approach. In the present study, 23 breakpoint junctions of 9p21 deletions were cloned from 17 acute lymphoblastic leukemias of childhood, consisting of $8 \mathrm{~T}$ - and 9 B-lineage samples, for a total of 46 break- points (at least two breakpoints for each case; some cases had different breakpoints in each homologue). Our aim was to examine which specific sequences, if any, are responsible for the deletion and if genomic architecture acts as susceptibility factor for the deletion itself.

The deletions we analyzed vary between $35 \mathrm{~kb}$ and $17 \mathrm{Mb}$ in size: $33 \%$ of them are homozygous, and $44 \%$ smaller than $1 \mathrm{Mb}$. Breakpoint junction cloning revealed that half of the breakpoints (11/24 and 12/22 in T- and BALL cases, respectively) were flanked by sequences similar to the heptamer-recombination signal sequences (heptamerRSSs), which are targeted by the RAG complex in V(D)J recombination. This mechanism, identified in 9p21 deletions since 1997 (Cayuela et al. 1997), is applicable to about half of the childhood ALLs, at odds with a recent 
Table 1 Sequences of all characterized breakpoints in childhood ALLs

\begin{tabular}{|c|c|c|c|c|c|c|c|}
\hline Case & $\mathrm{ALL}^{\mathrm{a}}$ & Breakpoint $^{\mathrm{b}}$ & Position $^{\mathrm{c}}$ & & Sequence $^{\mathrm{d}}$ & & Repeats $^{\mathrm{f}}$ \\
\hline \multirow{4}{*}{ 1460-07 } & \multirow{4}{*}{$\mathrm{T}$} & \begin{tabular}{|l} 
Distal BP1 \\
Junction 1 \\
Proximal BP1
\end{tabular} & $\operatorname{chr} 9: 22098125-22098190$ & 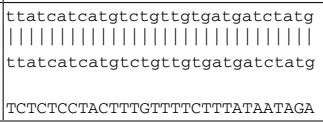 & $\begin{array}{l}\text { attaat } \\
\text { III\|\| } \\
\text { ATTAAT } \\
\|\|\|\| \\
\text { ATTAAT }\end{array}$ & $\begin{array}{l}\text { gatctttgaagttacgattgtaattgtttt } \\
\text { CTCTGAAAAGTAACTTTACTGTATTCTGAT } \\
\text { || | | | | | | | | | | | | | | | | | | | | | | } \\
\text { CTCTGAAAAGTAACTTTACTGTATTCTGAT }\end{array}$ & Tigger1 \\
\hline & & Distal BP2 & chr9:21552789-21552848 & $\begin{array}{l}\text { AATAAGCTTTTATGTGGAAGTTAGCAGATA } \\
|||||||||||||||||||||||||||| \mid)\end{array}$ & & ATTTCAGTTTAAGTGATTTGACTGATGACA & \\
\hline & & Junction 2 & & AATAAGCTTTTATGTGGAAGTTAGCAGATA & $\mathrm{CG}^{\mathrm{e}}$ & AGAAGAAAGCAGTCCTGCTACAGAAAATtt & \\
\hline & & Proximal BP2 & chr9:22545710-22545769 & ggccCCaCATAGGTGGGCATCAAATGATAA & & $\underset{\text { AGAAGAAAGCAGTCCTGCTACAGAAAATtt }}{\|\|}$ & LTR16D/L1MD \\
\hline 547-07 & $\mathrm{T}$ & \begin{tabular}{|l|} 
Distal BP \\
Junction \\
Proximal BP
\end{tabular} & chr9: 21983793-21983852 & $\begin{array}{l}\text { gtcattttgataatggccattgtggectgg } \\
\text { ||||||||||||||||||||||||||||||| } \\
\text { gtcattttgataatggccattgtggcctgg } \\
\text { TCCTACtgtgtgtgtgtgtgtgtgtgtgtg }\end{array}$ & AGG & $\begin{array}{l}\text { cacagtggttcacgectgtaatcctagcac } \\
\text { tgtgtgtgtgtgtgtgtgtgtgtCTTAGTC } \\
\text { || || || || || || || || || || || || || || ||| } \\
\text { tgtgtgtgtgtgtgtgtgtgtgtCTTAGTC }\end{array}$ & L1MA7/AluJB \\
\hline $218-07$ & $\mathrm{~T}$ & \begin{tabular}{|l|} 
Distal BP \\
Junction \\
Proximal BP
\end{tabular} & chr9:21527711-21527770 & $\begin{array}{l}\text { aatactttacagacaagcaaatgetgagag } \\
\text { ||||||||||||||||||||||||||||||| } \\
\text { aatactttacagacaagcaaatgctgagag } \\
\text { AGTTCTCCAAGGCAGTATGGTACTTCTCTA }\end{array}$ & GG & 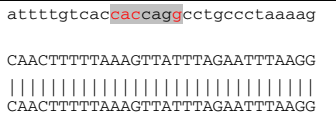 & L1PA2 \\
\hline $1562-06$ & $\mathrm{~T}$ & \begin{tabular}{|l|} 
Distal BP \\
Junction \\
Proximal BP
\end{tabular} & chr9:21909987-21910046 & $\begin{array}{l}\text { gaacttgtctctaatcctaatgtaacagaa } \\
\text { ||||||||||||||||||||||||||||||| } \\
\text { gaacttgtctctaatcctaatgtaacagaa } \\
\text { ATTATCAGCTTGGATCACATGGACTTGGGG }\end{array}$ & & 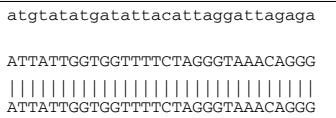 & MGR75B \\
\hline $217-07$ & $\mathrm{~T}$ & $\begin{array}{l}\text { Distal BP } \\
\text { Junction } \\
\text { Proximal BP }\end{array}$ & chr9:21815531-21815590 & 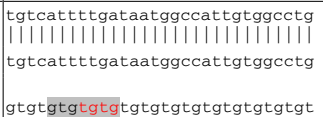 & TTTAAGTAAG & 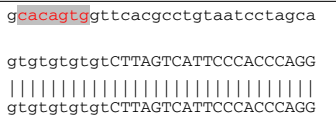 & L1MA7/AluJB \\
\hline \multirow{2}{*}{$147-07$} & \multirow{2}{*}{$\mathrm{T}$} & $\begin{array}{l}\text { Distal BP1 } \\
\text { Junction } 1 \\
\text { Proximal BP1 }\end{array}$ & $\operatorname{chr} 9: 22440703-22440762$ & $\begin{array}{l}\text { aacatgacgttttacatttaggaaaagaaa } \\
\text { |1 |||||||||||||||||||||||||||| } \\
\text { aacatgacgttttacatttaggaaaagaaa } \\
\text { ATTTAGGAAGATCCCACACAACCAAGATAG }\end{array}$ & TСTTAGTCCCAA & $\begin{array}{l}\text { ggactggtttgccagaattaatttggcaaa } \\
\text { AACAGACAGTGTGCCATATTGGTGTTATGC } \\
\text { || || || || || || || || || || || || || || ||| } \\
\text { AACAGACAGTGTGCCATATTGGTGTATGC }\end{array}$ & L2 \\
\hline & & \begin{tabular}{|l|} 
Distal BP2 \\
Junction 2 \\
Proximal BP2
\end{tabular} & chr9:21831409-21831468 & $\begin{array}{l}\text { gctaaccagagatcctgaatatgtccacat } \\
\text { |||||||||||||||||||||||||||||| } \\
\text { gctaaccagagatcctgaatatgtccacat } \\
\text { gaggcagataggagggtgggcactaattca }\end{array}$ & TAAT & 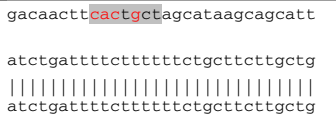 & L1PB1 \\
\hline \multirow[t]{3}{*}{$1321-07$} & \multirow[t]{3}{*}{$\mathrm{T}$} & $\begin{array}{l}\text { Distal BP1 } \\
\text { Junction } 1 \\
\text { Proximal BP1 }\end{array}$ & $\begin{array}{l}\text { chr9:21435322-21435381 } \\
\text { chr9:23928414-23928473 }\end{array}$ & 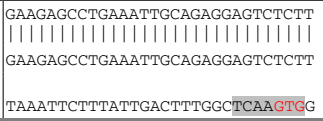 & GTGT & 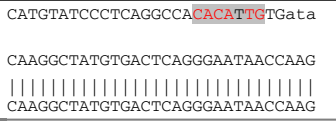 & (TA)n \\
\hline & & Distal BP2 & chr9:21788241-21788300 & 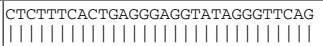 & & GGCTTAATCTTACACTTTGCTTATCCTATA & \\
\hline & & $\begin{array}{l}\text { Junction } 2 \\
\text { Proximal BP2 }\end{array}$ & $\operatorname{chr} 9: 24962814-24962873$ & $\begin{array}{l}\text { СTCTTTCACTGAGGGAGGTATAGGGTTCAG } \\
\text { AACaaatttaattttaaatattgtaattta }\end{array}$ & TCAT & 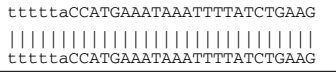 & AT-rich \\
\hline \multirow{2}{*}{$219-07$} & \multirow{2}{*}{$\mathrm{T}$} & $\begin{array}{l}\text { Distal BP1 } \\
\text { Junction } 1 \\
\text { Proximal BP1 }\end{array}$ & chr9:21055684-21055743 & $\begin{array}{l}\text { TTATATTCAAAGAGATGCTGGAACGAGGAA } \\
\text { || || || || || || || || || || || || || || || } \\
\text { TTATATTCAAAGAGATGCTGGAACGAGGAA } \\
\text { AGACATCTGATTATAATCAGTACTCTATTT }\end{array}$ & CCC chr9:22709999-22710226(rev) & $\begin{array}{l}\text { GAGGTTAAAGAGAGATTATTTGCCATCTTG } \\
\text { ATTCTTACTATATAACATTAGGTGCTTCCA } \\
\text { || || || || | | | | | | | | | | | | | | | | || | } \\
\text { ATTCTTACTATATAACATTAGGTGCTTCCA }\end{array}$ & \\
\hline & & \begin{tabular}{|l} 
Distal BP2 \\
Junction 2 \\
Proximal BP2
\end{tabular} & chr9:21738571-21738630 & $\begin{array}{l}\text { GTGAAGAATCTGAGCTTCCTAGATCTTatc } \\
\text { || || ||||||||||||||||||||||||||||||| } \\
\text { GTGAAGAATCTGAGCTTCCTAGATCTTatc } \\
\text { caaacttctatttgtctaaggaattttaag }\end{array}$ & chr4 : 163284405-163284832 & $\begin{array}{l}\text { tgatctaaatcctgcctctgtcagatctt } \\
\text { gtattctgttaattacagGTAAAACAGCAA } \\
\text { || ||||||||||||||||||||||||||||||||||| } \\
\text { gtattctgttaattacagGTAAAACAGCAA }\end{array}$ & MLT1J \\
\hline \multirow[t]{2}{*}{$402-06$} & \multirow[t]{2}{*}{ B } & $\begin{array}{l}\text { Distal BP } \\
\text { Junction }\end{array}$ & chr9:19785967-19786027 & $\begin{array}{l}\text { tagggacatggatgaagctggaaaccatca } \\
\text { |l||l||l||l||l||l||l||l||l||l|| } \\
\text { tagggacatggatgaagctggaaaccatca }\end{array}$ & GGCG & $\begin{array}{l}\text { ttctcagcaaactatcgtaaggacaaaaaac } \\
\text { gtgtatcatacattttcatggataaaaaga }\end{array}$ & LIPA4 \\
\hline & & & chr9:22514478-22514537 & & & $\begin{array}{l}\text { || || || || || || || || || || || || || || || || || } \\
\text { gtgtatcatacattttcatggataaaaaga }\end{array}$ & L3 \\
\hline
\end{tabular}

estimate (Kohno and Yokota 2006). In physiological V(D)J recombination, several nucleotides are often added at DNA ends before joining to increase the diversity of immunoglobulin and $\mathrm{T}$ cell receptor gene products (Meier and Lewis 1993). It must be noted that we found nucleotide insertions, from 1 to 12 nucleotides, at the breakpoint junctions of 9p21 deletions in the majority (20/23) of the junctions, not just where RSSs-like heptamer sequences were present, in accordance with the finding that $10-20 \%$ of non-homologous junction in mammalian cells have nucleotides inserted at the junction (Roth et al. 1989). In one case (219-07), the inserted sequence was longer (427 bp) and came from $4 \mathrm{q} 32.3$, underscoring the complexity of rearrangement events in cancer cells (Bignell et al. 2007).

Although many studies on cancer-related structural variations report microhomology at the junctions in a large proportion of the rearrangements (Bignell et al. 2007), we found only a single case with an overlap of six nucleotides (1460-07). In our cohort, the great majority of the junctions have no homology between distal and proximal ends (22/23, 95\%). The breakpoints fall only partially into previously identified cluster sites (Kohno and Yokota 1999) with two notable exceptions. In one case (1329-07), the proximal breakpoint overlaps the breakpoint of three previously analyzed lines, 
Table 1 continued

\begin{tabular}{|c|c|c|c|c|c|c|c|}
\hline \multirow{2}{*}{$888-06$} & \multirow{2}{*}{ B } & \begin{tabular}{|l|} 
Distal BP1 \\
Junction 1 \\
Proximal BP1
\end{tabular} & chr9:21931325-21931384 & $\begin{array}{l}\text { GGCTAATATCAAGATTAGCACTAGCTGTCT } \\
|||||||||||||||||||||||||||||| \\
\text { GGCTAATATCAAGATTAGCACTAGCTGTCT } \\
\text { gacattttttcctttactagccaaaaGGGA }\end{array}$ & AGT & $\begin{array}{l}\text { GTAGATACCATTTAGAAAAGTTTTCTCTAC } \\
\text { GAACAATAAGCAAATAAATTCAATTTTCTC } \\
\text { || || || | | | | | | | | | | | | | | | | | | | } \\
\text { GAACAATAAGCAAATAAATTCAATTTTCTC }\end{array}$ & simple repeat \\
\hline & & \begin{tabular}{|l} 
Distal BP2 \\
Junction 2 \\
Proximal BP2
\end{tabular} & $\begin{array}{l}\text { chr9:22486498-22486557 } \\
\text { chr9:22494315-22494374 }\end{array}$ & 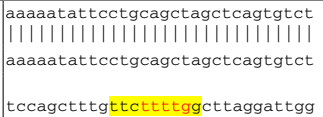 & T & 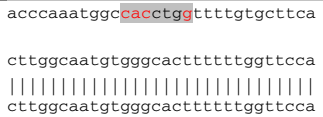 & L1PA7 \\
\hline 46-07 & B & $\begin{array}{l}\text { Distal BP } \\
\text { Junction } \\
\text { Proximal BP }\end{array}$ & chr9:21823933-21823992 & 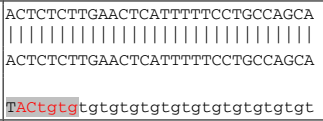 & TGAGAA & $\begin{array}{l}\text { CACATCATTTTGTCTCCTTTACTTTTCCAT } \\
\text { gtgtgtgtgtgtgtgtgtgtCTTAGTCATT } \\
\text { ||||||||||||||||||||||||||||||||||| } \\
\text { gtgtgtgtgtgtgtgtgtgtCTTAGTCATT }\end{array}$ & $(\mathrm{TG}) \mathrm{n}$ \\
\hline \multirow{2}{*}{$314-07$} & \multirow{2}{*}{ B } & \begin{tabular}{|l} 
Distal BP1 \\
Junction 1 \\
Proximal BP1
\end{tabular} & $\operatorname{chr} 9: 20598253-20598312$ & $\begin{array}{l}\text { ATGACAGTCTTTTTATTTGTAGTTGATTTT } \\
\text { || || |||||||||||||||||||||||||||||||||||| } \\
\text { ATGACAGTCTTTTATTTGTAGTTGATTTT } \\
\text { gagcattttttcatgtctgttggecgcata }\end{array}$ & GGGCTCCCCGC & 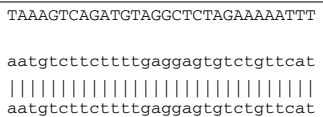 & L1PA7 \\
\hline & & \begin{tabular}{|l} 
Distal BP2 \\
Junction 2 \\
Proximal BP2
\end{tabular} & $\operatorname{chr} 9: 22494315-22494374$ & $\begin{array}{l}\text { aaaaatattcctgcagctagctcagtgtct } \\
\text { |||||||||||||||||||||||||||||| } \\
\text { aaaaatattcctgcagctagctcagtgtct } \\
\text { tccagctttgttcttttggcttaggattgg }\end{array}$ & T & $\begin{array}{l}\text { acccaaatggccacctggttttgtgcttca } \\
\text { cttggcaatgtgggcacttttttggttcca } \\
\text { |||||||||||||||||||||||||||||||||| } \\
\text { cttggcaatgtgggcacttttttggttcca }\end{array}$ & L1PA7 \\
\hline $1327-07$ & B & $\begin{array}{l}\text { Distal BP } \\
\text { Junction } \\
\text { Proximal BP }\end{array}$ & chr9:21915849-21915908 & 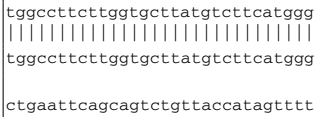 & & $\begin{array}{l}\text { caattatcctccaaggtgatggggttaaat } \\
\text { catccttaaccacaatactctaTGAATCCT } \\
\text { || || || || || || || || || || || || || || || | } \\
\text { catccttaaccacaatactctaTGAATCCT }\end{array}$ & MER50-int \\
\hline $1329-07$ & B & $\begin{array}{l}\text { Distal BP } \\
\text { Junction } \\
\text { Proximal BP }\end{array}$ & chr9:21965776-21965835 & $\begin{array}{l}\text { AAAAGTGCTCAGTGTTCTAGAAGCAGAGTT } \\
|||||||||||||||||||||||||||||| \\
\text { AAAAGTGCTCAGTGTTCTAGAAGCAGAGTT } \\
\text { ACATAAAAGGAACTAAGTACTGTGGTTGAG }\end{array}$ & CTCGA & $\begin{array}{l}\text { GCACAGTGATCCAAAGACCAGCTTCAAATA } \\
\text { GAATCCCGTCTCATTCTCAATTAACCTCTA } \\
\text { || | | | | | | | | | | | | | | | | | } \\
\text { GAATCCCGTCTCATTCTCAATTAACCTCTA }\end{array}$ & \\
\hline $886-07$ & B & $\begin{array}{l}\text { Distal BP } \\
\text { Junction } \\
\text { Proximal BP }\end{array}$ & $\operatorname{chr} 9: 21277034-21277093$ & 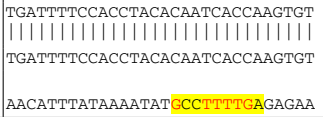 & ССстAтC & $\begin{array}{l}\text { AAGTTCACAAAATATAATGCAGCAAAATTG } \\
\text { AACACTAGAATTGGAATGGCCTTGAAGGTG } \\
\text { || || || || | | | | | | | | | | | | | | | | | } \\
\text { AACACTAGAATTGGAATGGCCTTGAAGGTG }\end{array}$ & \\
\hline $1623-06$ & B & \begin{tabular}{|l} 
Distal BP \\
Junction \\
Proximal BP
\end{tabular} & $\operatorname{chr} 9: 21106872-21106931$ & 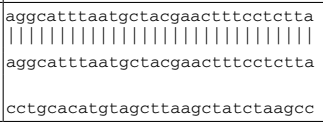 & chr9: 21106887-21107155(rev) CCCCCCT & $\begin{array}{l}\text { gcaccacttttgctgtatcccggaagtttt } \\
\text { ttagttagttttgtcatcagtcaaagggga } \\
\text { |||||||||||||||||||||||||||||||||||| } \\
\text { ttagttagttttgtcatcagtcaaagggga }\end{array}$ & L1PB7 \\
\hline $1063-07$ & B & $\begin{array}{l}\text { Distal BP } \\
\text { Junction } \\
\text { Proximal BP }\end{array}$ & chr9:20578216-20578275 & $\begin{array}{l}\text { cagtaccatgctgttttggtgactgtagec } \\
\text { IIIIIIIIIIIIIIIIIIIIIIIIIIII } \\
\text { cagtaccatgctgttttggtgactgtagce } \\
\text { agattccctgatttctagggattatggace }\end{array}$ & CCTTAAGG & $\begin{array}{l}\text { ttgtagtatagtttgaagtcaggtagtgtg } \\
\text { CcatttaggaaactctgCTCTAAGGAATTA } \\
\text { | | | | | | | | | | | | | | | | | | | | | | | | } \\
\text { CCatttaggaaactctgCTCTAAGGAATTA }\end{array}$ & L1PA3 \\
\hline
\end{tabular}

a ALL classification (T-ALL or B-ALL)

${ }^{b}$ BP1 and BP2 always refer to the two alleles in heterozygous deletions except for 888-06 and 314-07, where BP2 is a copy number variation

${ }^{c}$ Breakpoint position (hg18 assembly); the position of distal and proximal reference sequences is indicated

${ }^{\mathrm{d}}$ Sequence of breakpoint junctions aligned to the reference sequences; repeated sequences are shown in lowercase letters

e Additional bases not present in the reference sequence are shown in bold; inversions (in 219-07 Bp1 and 1623-06) and long insertions (in 219-07 Bp2) are also indicated. RSS motifs are highlighted in grey (heptamer) and yellow (nonamer); bases matching the motif consensus sequences are red

${ }^{\mathrm{f}}$ Repeated sequences located within $60 \mathrm{bp}$ from the breakpoints

BCS-LL3 (Kitagawa et al. 2002); this sequence has a V(D)J recombination potential only 150 -fold lower than the canonical consensus recombination signal sequence (Kitagawa et al. 2002). In three cases (547-07, 217-07 and 46-07), the distal breakpoint falls in the same (GT) ${ }_{n}$ repeat identified as BCS-LL2 in previous reports (Kitagawa et al. 2002). This site does not show unusual V(D)J recombination potential, but the $(\mathrm{GT})_{n}$ tract could adopt a non-B DNA structure (Bacolla and Wells 2004), which might enhance its potential for doublestrand break formation. The repeat is contained in the D9S1748 STS and shows a considerable degree of polymorphic variation. Typing of our samples for D9S1748 did not reveal any association between breakpoints within BCS-LL2 and any specific D9S1748 allele (not shown).
Polymorphism at D9S1748 does not seem to be a predisposing factor for chromosome 9p deletion in ALL.

Alterations in the regulation and pattern of DNA methylation are essential for tumor progression. Our analysis of $C D K N 2 A$ and $C D K N 2 B$ promoters showed that methylation took place in all cases without homozygous deletion. Similar data have been reported for $9 \mathrm{p} 21$ deletions found in other tumors, supporting the concept that, in accordance with the two-hit hypothesis (Knudson 1971), hypermethylation of promoter-associated CDKN2A and $C D K N 2 B$ CpG islands is the primary mechanism acting to inactivate the second allele in cases with a heterozygous deletion (Knudson 2001). According to our data, no relationship seems to exist between the size or 


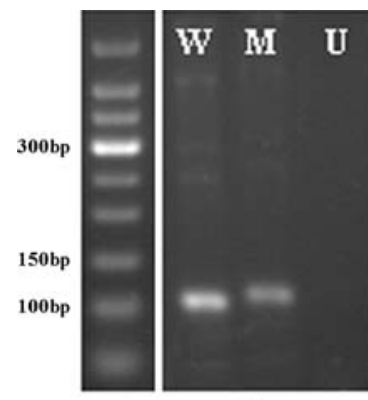

a

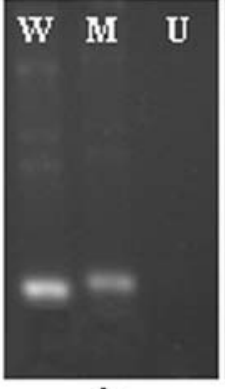

b

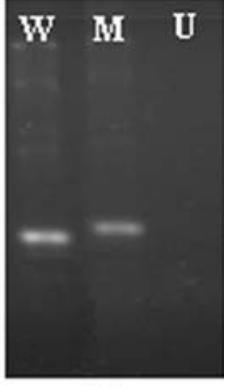

C
Fig. 3 MS-PCR analysis for $C D K N 2 A$ and $C D K N 2 B$ showing the products from wild-type/unmodified DNA $(W)$, unmethylated bisulfite-modified DNA $(U)$ and methylated bisulfite-modified DNA $(M)$. On the left: molecular weight marker (GelPilot $50 \mathrm{bp}$ ). a, b, and $\mathbf{c}$ MSPCR products using specific primers for p16INK4a, p14ARF and p15INKb, respectively, from case 1623-06

structure of the heterozygous deletion and the ability of the remaining allele to undergo promoter methylation.

In conclusion, our data show that different molecular mechanisms underlie the 9p21 deletion in childhood ALL. In half of the cases, the deletion is mediated by ectopic V(D)J recombination at RSSs-like sequences. Microhomology-mediated deletion, reported as frequent in cancer structural variations, was found only in one case. In the remaining cases, repeated sequences, including $(\mathrm{GT})_{n}$, with left-handed Z-DNA conformation potential, were detected at the breakpoint junctions. Insertions are common at breakpoint junctions. We identified only two cases sharing identical deletions. Four of our 46 breakpoints coincide with previously reported breakpoints, thus confirming the presence of recurrent deletion hotspots. In general, most of the breakpoints are non-recurrent and generate deletions of variable size. Our data partially answer the unsolved questions stressed by Kohno and Yokota (2006) showing that the chromatin architecture that makes DNA susceptible to DSBs is similar to the one detected in constitutional genomic disorders, with repeated sequences regions of DNA with non-B conformation potential playing a crucial role in predisposing to genome instability (Bacolla and Wells 2004; Wells 2007). However, we cannot exclude that deletion occurrence may also be influenced by other factors, such as interaction between cis- (Jones et al. 2009; Olcaydu et al. 2009; Kilpivaara et al. 2009) and trans-acting elements, as recently suggested in mouse meiotic recombination (Parvanov et al. 2009). Further studies are necessary to find out which haplotypes, if any, predispose to these somatic rearrangements.

Acknowledgments This work was supported by grants from AIRC (Associazione Italiana Ricerca sul Cancro), CNR (Consiglio Nazionale delle Ricerche), MIUR (Ministero dell'Istruzione e dell'Università),
European Union (FP6 program ALLOSTEM), Fondazione IRCCS Policlinico San Matteo to F.L., and CARIPLO (grant 2007.5197) to O.Z.

Open Access This article is distributed under the terms of the Creative Commons Attribution Noncommercial License which permits any noncommercial use, distribution, and reproduction in any medium, provided the original author(s) and source are credited.

\section{References}

Akamatsu Y, Tsurushita N, Nagawa F, Matsuoka M, Okazaki K, Imai M, Sakano H (1994) Essential residues in V(D)J recombination signals. J Immunol 153:4520-4529

Bacolla A, Wells RD (2004) Non-B DNA conformations, genomic rearrangements, and human disease. J Biol Chem 279:4741147414

Bertin R, Acquaviva C, Mirebeau D, Guidal-Giroux C, Vilmer E, Cave $\mathrm{H}$ (2003) CDKN2A, CDKN2B, and MTAP gene dosage permits precise characterization of mono- and bi-allelic 9p21 deletions in childhood acute lymphoblastic leukemia. Genes Chromosomes Cancer 37:44-57

Bignell GR, Santarius T, Pole JC, Butler AP, Perry J, Pleasance E, Greenman C, Menzies A, Taylor S, Edkins S, Campbell P, Quail M, Plumb B, Matthews L, McLay K, Edwards PA, Rogers J, Wooster R, Futreal PA, Stratton MR (2007) Architectures of somatic genomic rearrangement in human cancer amplicons at sequence-level resolution. Genome Res 17:1296-1303

Bruder CE, Piotrowski A, Gijsbers AA, Andersson R, Erickson S, de Ståhl TD, Menzel U, Sandgren J, von Tell D, Poplawski A, Crowley M, Crasto C, Partridge EC, Tiwari H, Allison DB, Komorowski J, van Ommen GJ, Boomsma DI, Pedersen NL, den Dunnen JT, Wirdefeldt K, Dumanski JP (2008) Phenotypically concordant and discordant monozygotic twins display different DNA copy-number-variation profiles. Am J Hum Genet 82:763771

Bungaro S, Dell'Orto MC, Zangrando A, Basso D, Gorletta T, Lo Nigro L, Leszl A, Young BD, Basso G, Bicciato S, Biondi A, te Kronnie G, Cazzaniga G (2009) Integration of genomic and gene expression data of childhood ALL without known aberrations identifies subgroups with specific genetic hallmarks. Genes Chromosomes Cancer 48:22-38

Campbell PJ (2009) Somatic and germline genetics at the JAK2 locus. Nat Genet 41(4):385-386

Cayuela JM, Gardie B, Sigaux F (1997) Disruption of the multiple tumor suppressor gene MTS1/p16(INK4a)/CDKN2 by illegitimate $\mathrm{V}(\mathrm{D}) \mathrm{J}$ recombinase activity in T-cell acute lymphoblastic leukemias. Blood 90:3720-3726

Cooper GM, Zerr T, Kidd JM, Eichler EE, Nickerson DA (2008) Systematic assessment of copy number variant detection via genomewide SNP genotyping. Nat Genet 40:1199-1203

de Smith AJ, Tsalenko A, Sampas N, Scheffer A, Yamada NA, Tsang P, Ben-Dor A, Yakhini Z, Ellis RJ, Bruhn L, Laderman S, Froguel P, Blakemore AI (2007) Array CGH analysis of copy number variation identifies 1284 new genes variant in healthy white males: implications for association studies of complex diseases. Hum Mol Genet 16:2783-2794

Drexler HG (1998) Review of alterations of the cyclin-dependent kinase inhibitor INK4 family genes p15, p16, p18 and p19 in human leukemia-lymphoma cells. Leukemia 12:845-859

Florl AR, Schulz WA (2003) Peculiar structure and location of 9p21 homozygous deletion breakpoints in human cancer cells. Genes Chromosomes Cancer 37:141-148 
Gil J, Peters G (2006) Regulation of the INK4b-ARF-INK4a tumour suppressor locus: all for one or one for all. Nat Rev Mol Cell Biol 7:667-677

Gu W, Zhang F, Lupski JR (2008) Mechanisms for human genomic rearrangements. Pathogenetics 1:4

Hesse JE, Lieber MR, Mizuuchi K, Gellert M (1989) V(D)J recombination: a functional definition of the joining signals. Genes Dev 3:1053-1061

Iafrate AJ, Feuk L, Rivera MN, Listewnik ML, Donahoe PK, Qi Y, Scherer SW, Lee C (2004) Detection of large-scale variation in the human genome. Nat Genet 36:949-951

Irving JA, Bloodworth L, Bown NP, Case MC, Hogarth LA, Hall AG (2005) Loss of heterozygosity in childhood acute lymphoblastic leukemia detected by genome-wide microarray single nucleotide polymorphism analysis. Cancer Res 65:3053-3058

Jones AV, Chase A, Silver RT, Oscier D, Zoi K, Wang YL, Cario H, Pahl HL, Collins A, Reiter A, Grand F, Cross NC (2009) JAK2 haplotype is a major risk factor for the development of myeloproliferative neoplasms. Nat Genet 41(4):446-449

Kilpivaara O, Mukherjee S, Schram AM, Wadleigh M, Mullally A, Ebert BL, Bass A, Marubayashi S, Heguy A, Garcia-Manero G, Kantarjian H, Offit K, Stone RM, Gilliland DG, Klein RJ, Levine RL (2009) A germline JAK2 SNP is associated with predisposition to the development of JAK2(V617F)-positive myeloproliferative neoplasms. Nat Genet 41(4):455-459

Kitagawa Y, Inoue K, Sasaki S, Hayashi Y, Matsuo Y, Lieber MR, Mizoguchi H, Yokota J, Kohno T (2002) Prevalent involvement of illegitimate $\mathrm{V}(\mathrm{D}) \mathrm{J}$ recombination in chromosome 9p21 deletions in lymphoblastic leukemia. J Biol Chem 277:46289-46297

Knudson AG Jr (1971) Mutation and cancer: statistical study of retinoblastoma. Proc Natl Acad Sci USA 68:820-823

Knudson AG (2001) Two genetic hits (more or less) to cancer. Nat Rev Cancer 1:157-162

Kohno T, Yokota J (1999) How many tumor suppressor genes are involved in human lung carcinogenesis? Carcinogenesis 20:14031410

Kohno T, Yokota J (2006) Molecular processes of chromosome 9p21 deletions causing inactivation of the p16 tumor suppressor gene in human cancer: deduction from structural analysis of breakpoints for deletions. DNA Repair (Amst) 5:1273-1281

Lam KW, Jeffreys AJ (2007) Processes of de novo duplication of human alpha-globin genes. Proc Natl Acad Sci USA 104(26):10950-10955

Liang Q, Conte N, Skarnes WC, Bradley A (2008) Extensive genomic copy number variation in embryonic stem cells. Proc Natl Acad Sci USA 105(45):17453-17456

Meier JT, Lewis SM (1993) P nucleotides in V(D)J recombination: a fine-structure analysis. Mol Cell Biol 13:1078-1092

Murao K, Kubo Y, Ohtani N, Hara E, Arase S (2006) Epigenetic abnormalities in cutaneous squamous cell carcinomas: frequent inactivation of the RB1/p16 and p53 pathways. Br J Dermatol 155:999-1005

Nobori T, Takabayashi K, Tran P, Orvis L, Batova A, Yu AL, Carson DA (1996) Genomic cloning of methylthioadenosine phosphorylase: a purine metabolic enzyme deficient in multiple different cancers. Proc Natl Acad Sci USA 93:6203-6208

Olcaydu D, Harutyunyan A, Jäger R, Berg T, Gisslinger B, Pabinger I, Gisslinger H, Kralovics R (2009) A common JAK2 haplotype confers susceptibility to myeloproliferative neoplasms. Nat Genet 41(4):450-454

Orlow I, LaRue H, Osman I, Lacombe L, Moore L, Rabbani F, Meyer F, Fradet Y, Cordon-Cardo C (1999) Deletions of the INK4A gene in superficial bladder tumors. Association with recurrence. Am J Pathol 155:105-113

Parvanov ED, Ng SH, Petkov PM, Paigen K (2009) Trans-regulation of mouse meiotic recombination hotspots by Rcr1. PLoS Biol 7(2):e36

Pieters R, Schrappe M, De Lorenzo P et al (2007) A treatment protocol for infants younger than 1 year with acute lymphoblastic leukaemia (Interfant-99): an observational study and a multicentre randomised trial. The Lancet 370:240-250

Roth DB, Chang XB, Wilson JH (1989) Comparison of filler DNA at immune, nonimmune, and oncogenic rearrangements suggests multiple mechanisms of formation. Mol Cell Biol 9:3049-3057

Ruas M, Peters G (1998) The p16INK4a/CDKN2A tumor suppressor and its relatives. Biochim Biophys Acta 1378:F115-F177

Sasaki S, Kitagawa Y, Sekido Y, Minna JD, Kuwano H, Yokota J, Kohno T (2003) Molecular processes of chromosome 9p21 deletions in human cancers. Oncogene 22:3792-3798

Strefford JC, Worley H, Barber K, Wright S, Stewart AR, Robinson HM, Bettney G, van Delft FW, Atherton MG, Davies T, Griffiths M, Hing S, Ross FM, Talley P, Saha V, Moorman AV, Harrison CJ (2007) Genome complexity in acute lymphoblastic leukemia is revealed by array-based comparative genomic hybridization. Oncogene 26:4306-4318

Turner DJ, Miretti M, Rajan D, Fiegler H, Carter NP, Blayney ML, Beck S, Hurles ME (2008) Germline rates of de novo meiotic deletions and duplications causing several genomic disorders. Nat Genet 40:90-95

Usvasalo A, Savola S, Räty R, Vettenranta K, Harila-Saari A, Koistinen P, Savolainen ER, Elonen E, Saarinen-Pihkala UM, Knuutila $S$ (2008) CDKN2A deletions in acute lymphoblastic leukemia of adolescents and young adults: an array CGH study. Leuk Res 32:1228-1235

van der Does-van den Berg, CR Bartram, G Basso et al (1992) Minimal requirements for the diagnosis, classification, and evaluation of the treatment of childhood acute lymphoblastic leukemia (ALL) in the "BFM Family" Cooperative Group. Med Pediatr Oncol 20:497-505

van Dongen JJ, Macintyre EA, Gabert JA, Delabesse E, Rossi V, Saglio G, Gottardi E, Rambaldi A, Dotti G, Griesinger F, Parreira A, Gameiro P, Diáz MG, Malec M, Langerak AW, San Miguel JF, Biondi A (1999) Standardized RT-PCR analysis of fusion gene transcripts from chromosome aberrations in acute leukemia for detection of minimal residual disease. Report of the BIOMED-1 Concerted Action: investigation of minimal residual disease in acute leukemia. Leukemia 12:1901-1928

Wells RD (2007) Non-B DNA conformations, mutagenesis and disease. Trends Biochem Sci 32:271-278 